\title{
Lessons and prospects of Universal Health Coverage in China: the importance of equity, quality, and affordability
}

\author{
Zhong $\mathrm{Li}^{1} \cdot$ Jun $\mathrm{Li}^{1}$ (i)
}

Received: 30 November 2018 /Revised: 15 February 2019 / Accepted: 28 February 2019 /

Published online: 12 March 2019

(C) National University of Singapore and Springer Nature Singapore Pte Ltd. 2019

\begin{abstract}
China's efforts in Universal Health Coverage (UHC) since the birth of the People's Republic in 1949 has passed four stages: (1) 1949-1983, Maoist UHC; (2) 1984-2003, Deng's Free-market healthcare experiment; (3) 2004-2008, response to people's call and restorative efforts; (4) 2009-present, reducing fragmentation, co-payment and improving primary care. The efforts of the first three stages aimed more at extending coverage and service scope, and those of the fourth stage for better equity, quality, and affordability. This article updates recent efforts in the fourth stage and looks ahead to the future after 2018, with the hope of providing references for the world in healthcare reform and development.
\end{abstract}

Keywords Universal Health Coverage $\cdot$ China $\cdot$ Health policy $\cdot$ Healthcare reform

\section{Introduction}

Healthcare is essential for the survival and development of human beings. Universal Health Coverage (UHC) had attracted considerable attention among scholars and governments in the world, and the WHO (Chan 2017). The WHO 2010 World Health Report proposed that a country moving towards universal coverage should consider three dimensions: the population (who is covered), the services (which services are included), and the direct costs (proportion of the costs that is covered). A country should move along all three dimensions, based on the available current pool of funds:

Jun Li

bjmulj@126.com

1 Peking University Institute for Medical Humanities, Beijing, China 
extending healthcare to the uncovered population, reduce cost sharing, and include additional services covered under the health insurance scheme (WHO 2010).

In 2018, the WHO put forward another document about UHC, where a new definition of UHC was given, emphasizing three new aspects: equal access, quality of the services provided, and the financial affordability (WHO 2018). This change may be seen as a recognition that it was not just formal coverage that was important but actual access to high-quality services for the whole country population.

This transition influenced the practice and discussion about UHC in many countries. For example, in Argentina, more attention was paid to the integration of different public medical insurance schemes so as to provide equal access to all nationals (Rubinstein 2018), although ensuring universal medical insurance coverage, or a more unified, equalized insurance system, does not necessarily lead to equal access (Das et al. 2018).

China now has better availability of healthcare resources (Marten et al. 2014, 21652166) and better health indicators (See Table 1) and has been commended for its achievements in healthcare in the past 60 years (Tang et al. 2012).

China had tried to improve its healthcare delivery system to ensure equal access, quality, and financial affordability since 1979 when the older system under the planned economy began to collapse. The Chinese government has built up and improved its three major social medial insurance schemes and covered most (99.36\%) of its population as of 2017. Recently, a series of measures such as enhancement of primary care have been introduced.

In this article, a brief background of UHC in China is presented, starting with a brief history of China's healthcare development since 1949, and followed by a summary of its public medical insurance system. Then we will present some current challenges to improve UHC in China. We will specifically focus on the need, as emphasized in the 2018 WHO report, to improve quality and enhance real access to healthcare services. The experience in China may provide useful information for other countries in their quest to improve healthcare for their populations.

\section{UHC in China: achievements and brief history since 1949}

\section{Achievements}

In the past 60 years, China has undergone tremendous changes in its health system. The core values of socialism, such as equality, have been manifest, sometimes more strongly than at other times. Healthcare policies have at times changed direction, in particular with the deepening of the market economy and the reform and opening-up policy.

As a result, a modernized healthcare system has been established covering both rural and urban areas and operating in both major cities and remote areas. With such advances, many indicators of health outcomes have improved. For example, the average life expectancy has increased from 35 years in 1949 to 76 years in 2015 (National Bureau of Statistics 2017). For more details of the current health status indicators, see Table 1.

\section{Brief history}

Since 1949, China's health system development has passed through four stages: (1) 1949-1983, Maoist UHC; (2) 1984-2003, Deng's free-market healthcare experiment; 
Table 1 Selected characteristics of healthcare system and health outcome in China in 2015

\begin{tabular}{|c|c|c|}
\hline Variable & \multicolumn{2}{|l|}{ Value } \\
\hline \multicolumn{3}{|l|}{ Health expenditure } \\
\hline Total & \multicolumn{2}{|c|}{4.63 trillion Yuan } \\
\hline Per capita & \multicolumn{2}{|c|}{3351.02 Yuan } \\
\hline Percentage of GDP & \multicolumn{2}{|l|}{$6.22 \%$} \\
\hline Public source (\% of total) & \multicolumn{2}{|c|}{$\begin{array}{l}41.21 \% \text { (private) } \\
30.01 \% \text { (government) } \\
28.78 \% \text { (social) }\end{array}$} \\
\hline \multicolumn{3}{|l|}{ Health insurance } \\
\hline Percentage of population covered in 2017 & \multicolumn{2}{|l|}{$99.36 \%$} \\
\hline Source of funding & \multicolumn{2}{|c|}{ Insurance contribution and taxes } \\
\hline \multicolumn{3}{|l|}{ Access } \\
\hline No of hospital beds per 10,000 population & \multicolumn{2}{|l|}{2.3} \\
\hline No. of physicians per 1000 population & \multicolumn{2}{|l|}{741.05} \\
\hline Life and death & Value & Urban/rural \\
\hline Life expectancy at birth in $2015^{a}$ & 76.3 years & - \\
\hline Annual no. of deaths per 1000 population & 7.09 people & - \\
\hline Annual no. of infant deaths per 1000 live births & 7.5 people & 4.2/9.0 people \\
\hline $\begin{array}{l}\text { Annual no. of deaths of children }<\text { five years of age } \\
\text { per } 1000 \text { live births }\end{array}$ & 10.2 people & $5.2 / 12.4$ people \\
\hline Annual no. of maternal deaths per 100,000 live births & 19.9 people & $19.5 / 20.0$ people \\
\hline \multicolumn{3}{|l|}{ Fertility and childbirth } \\
\hline Births attended by skilled health personnel in $2017(\%)$ & 91.6 & - \\
\hline Pregnant women receiving any prenatal care in $2017(\%)$ & 96.6 & - \\
\hline \multicolumn{3}{|l|}{ Prevalence of chronic diseases $(\%)$} \\
\hline Diabetes in persons $>18$ years of age (2013) & $35.1 \%$ & $48.9 \% o / 21.3 \%$ \\
\hline $\begin{array}{l}\text { Hypertension in persons > } 18 \text { years of age } \\
\quad \text { (total/male/female, } \% o, 2012 \text { ) }\end{array}$ & $\begin{array}{l}25.2(\mathrm{~T}) \\
26.2(\mathrm{M}) \\
24.1(\mathrm{~F})\end{array}$ & $\begin{array}{l}26.8(\mathrm{~T}, \mathrm{U}) / 23.5(\mathrm{~T}, \mathrm{R}) \\
28.1(\mathrm{M}, \mathrm{U}) / 24.2(\mathrm{M}, \mathrm{R}) \\
25.4(\mathrm{~F}, \mathrm{U}) / 22.8(\mathrm{~F}, \mathrm{R})\end{array}$ \\
\hline \multicolumn{3}{|l|}{ HIV infection } \\
\hline 54,360 incidence, 14,091 death (2016) 3.97/1.03 $(1 / 100,000)$ & & \\
\hline
\end{tabular}

Source of data: National Bureau of Statistics 2017

$T$ total, $U$ urban, $R$ rural, $M$ male, $F$ female

${ }^{a}$ Data Bank of the World Bank Group (2017)

(3) 2004-2008, response to people's call and restorative efforts; (4) 2009-present, enhanced privatization, re-investment in primary care and prevention, as well as reduction of healthcare system fragmentation and reduction of costs.

\section{$1949-1978$}

Before the 1980s, health policy under Mao Zedong was a highly salient and contentious issue. Mao and his colleagues in the Party central committee became directly involved in the policy-making process, minimizing the role of the Ministry of Health (Huang 2002). 
Since the 1950s, China has gradually established a healthcare system suitable for the planned economy, that is, the state provides public medical care and labor insurance benefits to employees of public institutions, and the state carries out financing, control, and organization of healthcare. The state owns all medical institutions and pays wages directly to all healthcare providers; neither private health insurance companies nor private health insurance companies exists. There were no private practitioners as well.

The orientation of industrialization makes the protection of the labor force in the industrial sector the preferred objective and value of the public policy as a whole. With limited resources, the principle of different welfare provision between urban and rural areas has been selected (Lin 2002, 91-95).

In urban areas, workers and even their family enjoyed free public healthcare. At that time, most of the Chinese urbanites were workers for government agencies or state-owned enterprises or collectively owned enterprises. Without public medical care or labor insurance medical benefits, the vast rural population lacked medical treatment and medicines. Therefore, farmers take the form of spontaneous mutual assistance to solve this problem.

In 1955, during the climax of rural cooperation, the cooperative medical system in rural areas emerged. Organized by agricultural production cooperatives, many health stations appeared in rural regions of Shanxi, Henan, and other provinces. The masses and the production cooperatives joint fund the system.

In November 1959, the National Conference on Rural Health Work was held in Jishan County, Shanxi Province. On 2 February 1960, the Central Committee of the Communist Party of China transmitted the report of the Ministry of Health on the National Conference on Rural Health Work and its annexes and asked all localities to refer to them for implementation. Since then, the cooperative medical system has become a primary system for the government for healthcare in rural areas of China. The large-scale popularization of cooperative medical care happened after 1966.

To fully implement Mao's ruling ideas, in which attention to rural medical care aimed to be equal to that of urban residents, massive medical personnel from all over the country were sent to the countryside with Mao's directive on June 26, 1965 (the 626 directive). After issuing the 626 directives, he promoted the construction of the rural cooperative medical system and the training of barefoot doctors.

Mainly conducted by the group of village practitioners, or so-called "barefoot doctors, the rural cooperative medical system performed well for rural primary care. During each consultation/hospitalization, patients only need to pay a little registration fee. To save money, commune officials carried out mass health campaigns to raise farmers' awareness of disease prevention. At the same time, barefoot doctors tend to use traditional Chinese medicine, and the communes were encouraged to grow herbs by themselves.

\section{9-2003}

The situation did not change until the late 1970s when Mao Zedong passed away and with that the dominant Maoist impact. The reform and opening-up policy adopted by the new Communist Party leader, Deng Xiaoping, began to sweep across all aspects of Chinese people's life. The economic reforms started in 1979 marked the overall recovery of the market economy in this socialist country, while the role of the government was gradually reduced in nearly all social sectors, including healthcare. 
Two significant changes occurred in the field of healthcare. One is that the collective agriculture in the countryside, the cornerstone of Maoist socioeconomic structure, disappeared. The other is that each level of subnational government became responsible for local healthcare, especially in terms of healthcare financing.

With limited budgets and lower development priority, local governments found it hard to fund the healthcare system, including the subsidy for millions of "barefoot doctors." Without enough financial support and effective control from the government, public hospitals and their employees began to act like for-profit entities in a mostly unregulated market (Blumenthal and Hsiao 2015).

Under such a circumstance, self-reliance became the law of survival for the whole healthcare sector. When the hospital earned more profits, physicians got more bonuses. For-profit behaviors directly drove the rise of healthcare prices, and the people who had been accustomed to socialist welfares had no choice but to accept a cruel fact that their healthcare was no longer affordable.

Furthermore, the reform left most of the population uninsured, since the government did not provide coverage and no private insurance industry existed. In 1999, 49\% of people in the urban areas had medical insurance, in contrast, only $7 \%$ of the 900 million rural Chinese had coverage (Blumenthal and Hsiao 2015).

Besides, from 2000 to 2003, hundreds of public hospitals were auctioned. Plans to privatize public hospitals quickly became a favorite way for many local government policymakers to ease the medical care burden and boost GDP growth. Under the impact of privatization, the original public health network has been dramatically weakened. The inadequate capacity to respond to sudden public health events has been exposed in following subsequent outbreaks of severe infectious diseases, including SARS and influenza A (H1N1).

A series of reforms on state-owned enterprises and the rural collective economy led to the rapid decline of the Chinese government's ability to invest in social and public services, including healthcare. The problem of affordability was made more acute by the high out-of-pocket share of individual medical expenses and the high price of healthcare.

The Third National Health Service Survey in 2003 (Ministry of Health Statistical Information Center 2005, 3-5) showed that $48.9 \%$ of urban and rural residents who should see a doctor did not see a doctor. Compared with the previous two surveys (1993 and 1998), the hospitalization rate of the low-income group decreased, that of the high-income group increased, and the gap between the high-income group and the lowincome group has increased from $17 \%$ in 1993 to $68 \%$ in 2003 . Of the discharged patients, $43.3 \%$ left on their own decision without a doctor's permission. Among these patients, $63.9 \%$ left the hospital due to economic difficulties, $53.0 \%$ in urban and $67.3 \%$ in rural areas respectively. After adjusting for the factor of the price increase, the outpatient visit medical expenses increased by 1.2 times as compared with $1993,87.5 \%$ as compared with 1998; the medical expenses per hospitalization increased by 1.5 times as much as in 1993 and $67.2 \%$ as in 1998 .

Furthermore, the outbreak of SARS around 2003 brought various problems in China's public health under the global spotlight. This event, like a spark, ignited the long-simmering social contradictions. It pushed the urgent medical reform across the whole field of healthcare to the forefront of public opinion, unveiling the curtain of China's healthcare reform in 2003. 


\section{3-2008}

From 2003, the state began to rebuild the social network of medical insurance and started to build the New Rural Cooperative Medical-care Scheme (NRCMS). Back in 1998, China had begun to establish the basic medical insurance system for urban workers and had launched the basic medical insurance for urban residents in 2007.

The current state-run medical insurance system in China mainly consists of three programs: the Basic Medical Insurance for Urban Workers (BMIUW), the Basic Medical Insurance for Urban Residents, and the New Rural Cooperative Medicalcare Scheme (NRCMS). The populations covered the sources of funds and the management differs among the schemes (for details see Table 2). For example, the BMIUW is eligible for those employed only.

For the Basic Medical Insurance for Urban Workers, a compulsory contribution of all of the urban employees, co-paid with their employers, is required, at a rate of $7 \%$ of their income. Both two sides cover a certain proportion of medical expenses, mainly for outpatient and inpatient services at hospitals, and the purchase of medicine at designated community pharmacies.

For the Basic Medical Insurance for Urban Residents, unemployed urban residents, including the elderly and children, have the right to decide whether or not to participate in the program. The government and the urban residents share its contribution.

The New Rural Cooperative Medical Service applies for people with rural Hukou are welcomed to join the program in the form of households. For both the second and the third one, financial support from the government plays a significant and decisive role.

In recent years, the latter two schemes have merged in 25 provinces (out of the 34 provinces and province-level regions), creating a new Urban and Rural Resident Basic Medical Insurance Scheme in each province. Furthermore, additional medical insurance programs exist for the three schemes. (In the latter part of this paper, if not otherwise specified, the three schemes will be referred to by an umbrella term: social medical insurance.)

Also, there is a "free" healthcare system, covering about $1 \%$ of the total population (China Statistics Yearbook 2017). The beneficiaries of this free system are mainly the government employees and future government employees, such as students of

Table 2 Specifics of insurance schemes

\begin{tabular}{llll}
\hline Category & Hukou type $^{\mathrm{a}}$ & Contribution type & Managing agency \\
\hline BMIUW & Urban & Compulsory, co-paid with their employers & Ministry of Labor and Social Security \\
BMIUR* & Urban & Voluntary, government subsidized & Ministry of Labor and Social Security \\
NRCMS & Rural & In the form of household & $\begin{array}{c}\text { National Health and Family Planning } \\
\text { Commission }\end{array}$ \\
& & & \\
\hline
\end{tabular}

\footnotetext{
${ }^{a}$ Hukou is the household registration system in China. A person has either an urban or a rural Hukou and that in the long term determines the social welfare one can obtain. In most cases, an urban Hukou guarantees better welfare

b Participants pay $7 \%$ of their income, and their employers pay an equal amount of money for them

c Participants include unemployed working-age adults, the elderly and children
} 
renowned universities. For the military, a separate system also exists. Commercial medical/health insurance is also sold by domestic, foreign, or Hong Kong medical/ health insurance companies to local citizens. With a severe problem of an aging population, some cities have piloted long-term care insurance programs.

Due to the vast territory and varied conditions in different provinces in China, the contribution, reimbursement rate, cap, deductible, reimbursable drugs, and reimbursable services of these schemes vary among provinces to some degree.

Worthy mentioning is the efforts and the results of the state to narrow the gap between the healthcare of urbanites and farmers and peasants. Up to date, $95 \%$ of rural households have joined the NRCMS scheme. With that, farmers and peasants could better afford healthcare, especially for routine surgery and disease management at the primary level, although the participants were encouraged to seek healthcare at the primary level, with the policy implemented since 2014, where costs incurred at lower level facilities could get a higher reimbursement rate. The main aim of this policy was to ease overcrowding in the regional hospitals caused by over-concentration of facilities and expertise in such hospitals, but the public also complained of the poor quality of primary care.

\section{9 to now}

The state started another round of healthcare reform, aiming at providing equal, affordable, accessible, and high-quality healthcare for all the citizens. Highlights of this era are (1) establishment of a unified medical insurance system for urban and rural residents; (2) the plan of transferring part of state-owned capital to enrich social security fund; (3) integrated reform of healthcare delivery, medical insurance, and drugs; (4) improvement of public hospitals; (5) abolishment of drug mark-up; and (6) the reform of the examination and approval system of pharmaceutical and medical devices. (Summarized by the authors from the Government Report of China 2010-2018).

\section{Challenges in UHC}

The 2009 round of healthcare reform, the latest round of such, has improved medical insurance coverage and healthcare access; however, many problems remain. While there is now formal universal coverage in the sense that everyone in China is covered by health insurance, challenges now remain related to equity, affordability, quality of the delivery system, and financing. We will now point out some of these challenges and how China deals with them.

\section{Equity and affordability}

In terms of equity, there are many issues as Chinese society now has a more considerable class difference than previously. Among these issues, there are two prominent ones related to healthcare: (1) fragmented medical insurance systems and (2) different reimbursement rate of social medical insurance. Before discussing the two issues, the reimbursement mechanisms of the SMI schemes is presented. 


\section{Reimbursement mechanisms of the schemes}

To regulate reimbursement and services, the Ministry of Human Resources and Social Security released the National List of Drugs for Basic Medical Insurance (referred to as the Drug List below), National List of Diagnosis and Treatment Items (referred to as the Services List below), National Standards of Healthcare Facilities (referred to as the Standards below). With reference to the national lists, each province made their lists. With the latest round of institutional reform, the list-making function was transferred to the newly established National Administration of Medical Insurance under the National Commission of Health.

Only drugs included in the Drug List given and services in the Services List received at the designated healthcare facilities, i.e., facilities meet the standards are reimbursable. Otherwise, patients must pay by themselves. Patients used to pay in full by themselves at the point of care delivery and get reimbursed later, and direct reimbursement had begun in recent years.

In general, these schemes have set the contribution, reimbursement rate, cap, deductible, reimbursable drugs, and reimbursable services. Take Beijing's Urban Workers' Scheme for example (Zhang 2015, 13-15). The contribution is paid jointly by employers and employees and is included in the insurance fund, which is divided into two parts: individual account and pooled fund. It is mainly used to pay for outpatient, emergency, hospitalization costs.

Medical expenses below the deductible line shall be paid from personal accounts, and when the balance of private accounts is insufficient, paid by individuals themselves. Medical fees above the deductible line and below the cap are mainly paid from the pooling fund, and individuals are required to bear a certain proportion. The standard of the deductible is controlled at about $10 \%$ of the average local annual wage, and the cap at about six times of it.

Participants of this scheme can choose several designated medical institutions to see a doctor, or they can buy drugs in designated pharmacies with the prescription with the hospital stamp allowing for out-of-hospital purchasing of drugs.

Reimbursement method: Medical expenses incurred in a settlement period (generally 1 year) shall be calculated by stages and paid accumulatively according to the hospital grade (hospitals are usually divided into community health service centers and primary, secondary, tertiary hospitals). The pooling fund and individuals shall share the expenses following the prescribed proportion (details see Tables 1 and 2). And below are the details for the payment scope of individual accounts and pooled fund.

One thing to be clarified is the in-theory reimbursement rates and the actual reimbursement rates. The in-theory reimbursement rates of the three schemes could be very high as shown in Tables 3 and 4 . However, the general public prefers to consider the actual reimbursement rate and found it dissatisfactory. For comparison, we used the method proposed by $\mathrm{Chu}$ (2013) to calculate the average actual reimbursement rate of the three systems (see Fig. 1). ${ }^{1}$

\footnotetext{
${ }^{1}$ We first used the total expenditure of each SMI divided by the number of the insured of each SMI to get the per-capita spending of the insured from each SMI. And we obtained the per-capita cash health expenditure (rural and urban data are available separately) to indicate the co-payment of the citizens for healthcare. The reimbursement rate = per-capita expenditure paid by each SMI / (per-capita expenditure paid by each SMI + per capita cash health payment) $* 100$. Chu used the same method.
} 


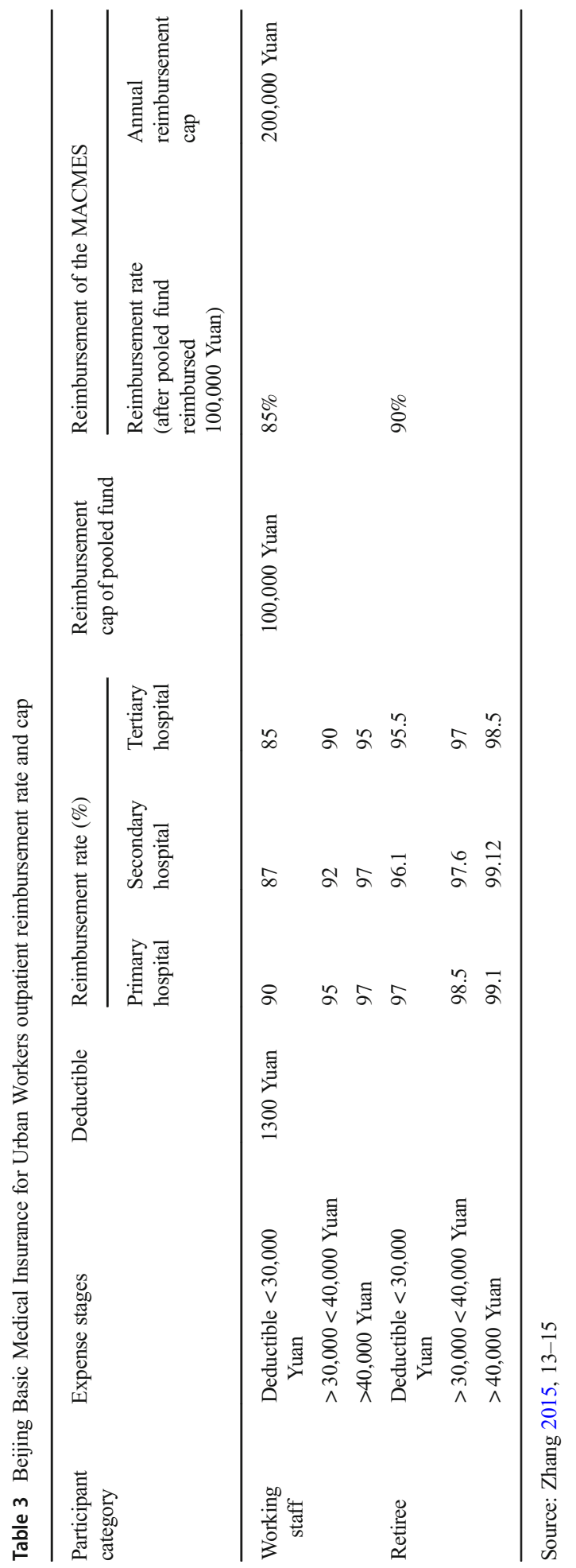


Table 4 Beijing Basic Medical Insurance for Urban Workers reimbursement rate and cap

\begin{tabular}{|c|c|c|c|c|c|}
\hline \multirow[t]{2}{*}{ Participant category } & & \multirow[t]{2}{*}{ Deductible (Yuan) } & \multicolumn{2}{|c|}{ Reimbursement rate $(\%)$} & \multirow[t]{2}{*}{ Cap (Yuan) } \\
\hline & & & $\begin{array}{l}\text { Community } \\
\text { health service }\end{array}$ & $\begin{array}{l}\text { Non-community } \\
\text { health service }\end{array}$ & \\
\hline \multirow{3}{*}{$\begin{array}{l}\text { Working staff } \\
\text { retiree }\end{array}$} & & 1800 & 90 & 70 & 20,000 \\
\hline & $<70$ years old & 1300 & 90 & 85 & 20,000 \\
\hline & $\geq 70$ years old & 1300 & 90 & 90 & 20,000 \\
\hline
\end{tabular}

Source: Zhang 2015, 13-15

\section{Government funding and individual contribution of the schemes}

According to the central government, the financial subsidy standard for the new rural cooperative medical system and urban residents' medical insurance increased from 120 Yuan per person per year in 2010 to 420 Yuan per person in 2016 (The People's Daily 2017). For the urban residents' medical insurance, according to the Beijing Social Security Bureau, the per-person annual individual contribution for urban elderly was 360 Yuan, for students and children 160 Yuan, for unemployed urban residents 660

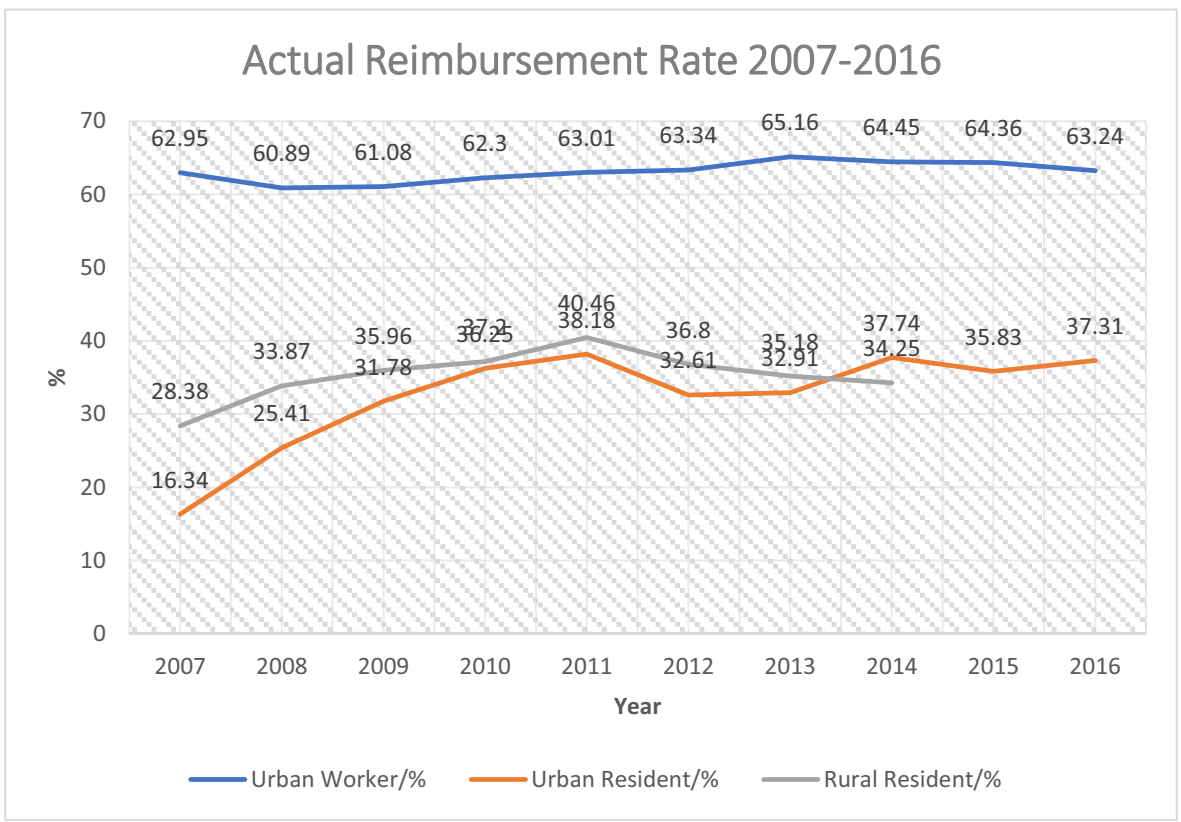

Fig. 1 Actual reimbursement rate of different medical insurance schemes. Data source: China Health and Family Planning Statistical Yearbook 2017. Some data are not available due to the merger of the urban residents and rural residents' schemes. Notes: Urban worker = basic medical insurance for urban workers, urban residents $=$ basic medical insurance for urban residents, rural residents $=$ new rural cooperative healthcare scheme 
Yuan, and for the disabled unemployed residents 360 Yuan (Beijing Social Insurance Fund Management Center 2017).

From 2013 to 2017, financial subsidies to urban and rural residents' medical insurance increased from 328.2 billion Yuan to 491.9 billion Yuan, an average annual increase of $10.6 \%$ (Liu 2018).

\section{Fragmentated medical insurance systems}

Fragmentation of the medical insurance systems has aroused increasing concern in both the academia and the public. Such systems can no longer meet people's demand when they are migrating from rural areas to urban areas and from one urban area to another which now happens much more frequently than under the planned economy time. With the problem of information segmentation, it is difficult for migrant workers from rural places to get timely and convenient service under their medical insurance policy in the city. Laid-off urban workers are confronted with the absence of health insurance coverage. Freelance residents with high income and chronic severe diseases are excluded from the insurance for urban workers, which has better benefits than the one for urban residents. The academia and the public expect the establishment of a center for planning and claims across the urban and rural areas, or a thorough merger between the separated systems to solve these problems (Wang 2017, 64-66).

\section{Divergent reimbursement rate of social medical insurance schemes}

In some provinces, the government claims that it reimburses $75 \%$ for several severe diseases (Wang 2017, 64-66); however, local people still complain about "impoverishment caused by illness". Such complaint may be explained by the fact that the actual reimbursement rates stand far below the theoretical reimbursement rates claimed by the government and variation in different schemes complicates the issue as well (see Fig. 1).

\section{Delivery system defects: a hindrance to quality and sustainability}

\section{Crowded public tertiary hospitals}

In China, most of the services are provided by public hospitals and higher-level hospitals outperformed lower level hospitals, so people would prefer to see doctors at the former, especially at tertiary hospitals (see Table 5). This fact gives these hospitals

Table 5 Visits at various levels of healthcare facilities (10,000 visits) and their percentages

\begin{tabular}{lllllll}
\hline & & Tertiary & Secondary & Primary & Unclassified & Total \\
\hline 2015 & Visits & $149,764.6$ & $117,233.1$ & $20,567.9$ & $20,798.5$ & $308,364.1$ \\
& $\%$ & 48.57 & 38.02 & 6.67 & 6.74 & 100 \\
\multirow{2}{*}{2016} & Visits & $162,784.8$ & $121,666.5$ & $21,790.9$ & $20,713.7$ & $326,955.9$ \\
& $\%$ & 49.79 & 37.21 & 6.66 & 6.34 & 100 \\
\hline
\end{tabular}


more stake to demand more financing and human resources and their leaders a bigger say in healthcare system reform.

\section{Weak primary care}

Before the reform in 2009, the prominent problem in primary care was the lack of financial support to health professionals at the grassroots level, especially those practicing in village and township health centers. Such insufficiency resulted in a widespread tendency in primary care: doctors tend to provide for-profit services through over-examination and self-paid medication, directly intensifying people's burden and the tension between patients and doctors. Furthermore, due to people's distrust towards the grassroots system, there is a large number of "idling" community service facilities in both rural and urban areas. Facilities without qualified staffing cause dangerous waste of healthcare resources and aggravate the burden of healthcare in higher-level facilities in urban areas (Wang 2017, 64-66).

The reform started in 2009 greatly enhanced input for primary care, especially for the facility. According to the Central Government Reports, in 2011, 1500 county hospitals, 500 county traditional Chinese medicine hospitals, 1000 county maternal and children hospitals, 23,000 town hospitals, and 2400 community health service centers were built or renovated (Wen 2011); in 2014, essential drugs were made available in $80 \%$ of village clinics ( $\mathrm{Li} 2014)$.

As a result, compared with 2008, the proportion of inpatients choosing primary healthcare institutions and county/city/district hospitals in urban areas increased by $5.1 \%$ and $3.9 \%$ respectively. In rural areas, the proportion of inpatients choosing primary healthcare institutions decreased slightly, from $36.6 \%$ in 2008 to $29.8 \%$ in 2013 . The ratio of inpatients choosing county/ city/district hospitals in rural areas increased slightly, by 5.7 percentage points (see Table 6).

From 2008 to 2013, the proportion of patients visiting medical institutions of different levels for the first time in 2 weeks was similar, but the flow of residents in urban areas changed. In urban areas, the proportion of first visits to primary medical institutions has increased (see Table 7).

However, the quality of healthcare at these primary facilities still falls short of the expectations. Although little literature reported about the quality of healthcare at these

Table 6 Composition of inpatient services by facility type in 2008 and 2013 (\%)

\begin{tabular}{|c|c|c|c|c|c|c|}
\hline \multirow[t]{2}{*}{ Facility type } & \multicolumn{2}{|c|}{ Urban and rural } & \multicolumn{2}{|c|}{ Urban } & \multicolumn{2}{|l|}{ Rural } \\
\hline & 2013 & 2008 & 2013 & 2008 & 2013 & 2008 \\
\hline Primary facilities & 21.0 & 28.7 & 11.8 & 6.7 & 29.8 & 36.6 \\
\hline County/city/district hospital & 51.6 & 48.2 & 47.3 & 43.4 & 55.7 & 50 \\
\hline Provincial/prefecture/municipal hospitals & 25.2 & 20.1 & 38.1 & 46.6 & 12.9 & 10.6 \\
\hline Others & 2.2 & 2.9 & 2.8 & 3.2 & 1.6 & 2.8 \\
\hline
\end{tabular}

Source: Center for Health Statistics and Information, NHFPC 2015 
Table 7 Composition of outpatient services within 2 weeks by facility type in 2008 and 2013 (\%)

\begin{tabular}{|c|c|c|c|c|c|c|}
\hline \multirow[t]{2}{*}{ Facility type } & \multicolumn{2}{|c|}{ Urban and rural } & \multicolumn{2}{|l|}{ Urban } & \multicolumn{2}{|l|}{ Rural } \\
\hline & 2013 & 2008 & 2013 & 2008 & 2013 & 2008 \\
\hline Primary facilities & 72.7 & 73.7 & 65.2 & 48.3 & 80.1 & 81.7 \\
\hline County/city/district hospital & 16.9 & 17.3 & 17.6 & 23.7 & 16.1 & 15.3 \\
\hline Provincial/prefecture/municipal hospitals & 8.2 & 7.9 & 14 & 26.6 & 2.5 & 2.1 \\
\hline Others & 2.2 & 1 & 3.1 & 1.4 & 1.4 & 0 \\
\hline
\end{tabular}

Source: Center for Health Statistics and Information, NHFPC 2015

facilities, the Highlights of Health Care made by the central government had been emphasizing on the improvement of quality, even in the year 2019 (National Health Commission 2019). As pointed out by some researchers, the key is the shortage of qualified personnel (Chen et al. 2013, 26-27).

\section{Dysfunctional financing: excessive share of pharmaceutical spending in health expenditure}

The insufficient financial input by the government to the health system forced the healthcare facilities to rely on profits from drug sales for survival and development. The high share of pharmaceutical spending ${ }^{2}$ in both inpatient and outpatient care could reflects this (see Figs. 2 and 3).

The profit from pharmaceutical sale even accounts for two thirds of the total profit at a certain tertiary A hospital with an annual profit of 150 to 200 million Yuan (or 25 to 33.33 million US dollars) (Li and Ye 2013, 103-104).

Furthermore, insufficient financing propels healthcare facilities to prefer highprofit drugs. To some extent, this induced the rapid rise in costs in various forms reported by pharmaceutical companies. The price was set by the NDRC and its subnational affiliations based on the crude costs reported by drug companies. Therefore, there is a large room for inflated price reporting. Pricing and drug share are very complicated topics and would have to be addressed in separate articles.

\footnotetext{
${ }^{2}$ In China, if not otherwise specified, pharmaceutical products refer to substances used to prevent, treat, and diagnose human diseases and purposefully regulate physiological functions, with prescribed indications or functional indications, usage, and dosage, including traditional Chinese medicines, Chinese patent medicines, active pharmaceutical ingredients and their preparations, antibiotics, biochemical drugs, radiopharmaceuticals, serum and vaccines, blood products, and diagnostic drugs (National People's Congress 2015). Pharmaceutical spending in this article (and in the data source- China Health and Family Planning Statistics Yearbook) refers to spending on the substances mentioned above, used either in outpatient care or inpatient care. When calculating pharmaceutical spending, both prescriptive and non-prescriptive drugs are included and the marked-up price, instead of the wholesale price, is used. Pharmaceutical spending and its share in total health expenditure in China should be cautiously interpreted when comparing with other data, for example, those by the OECD (OECD 2017), as they may differ in terms of the calculation method.
} 


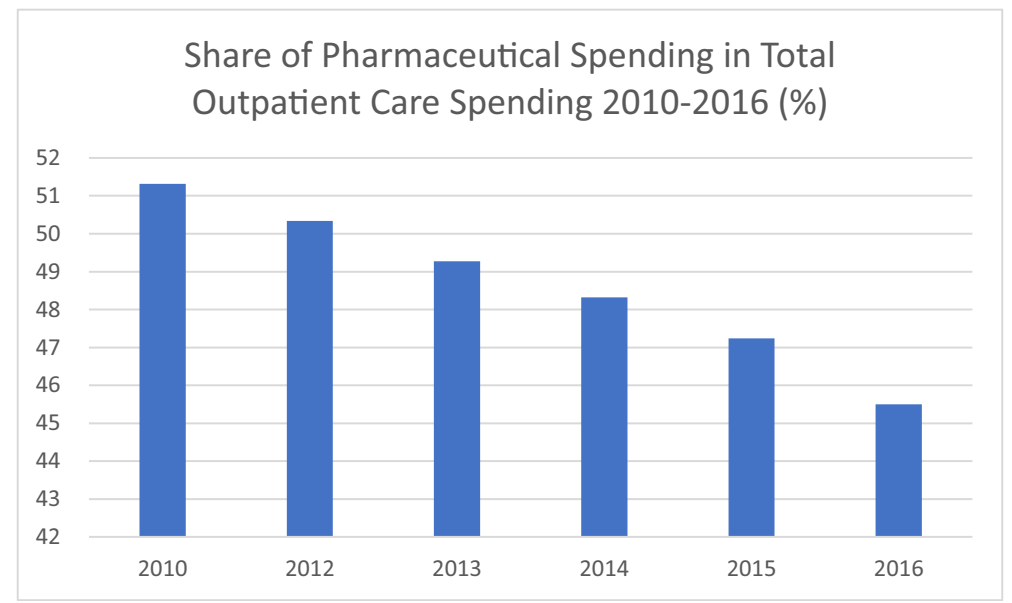

Fig. 2 Share of Pharmaceutical Spending in Total Outpatient Care Spending 2010-2016 (\%). Data source: China Health and Family Planning Statistical Yearbook 2017

\section{Countermeasures}

In recent years, a series of measures have been taken to resolve the problems in healthcare in China. Fragmentation was addressed by merging the New Rural Cooperative Health Care Scheme and the Urban Resident Basic Social Medical Insurance. Portability of insurance was further improved by launching real-time cross-provincial settlement of inpatient care fees. Medical alliances were encouraged for better care transition between different levels of healthcare facilities. Private capital was introduced into the healthcare market, in the hope of rivaling

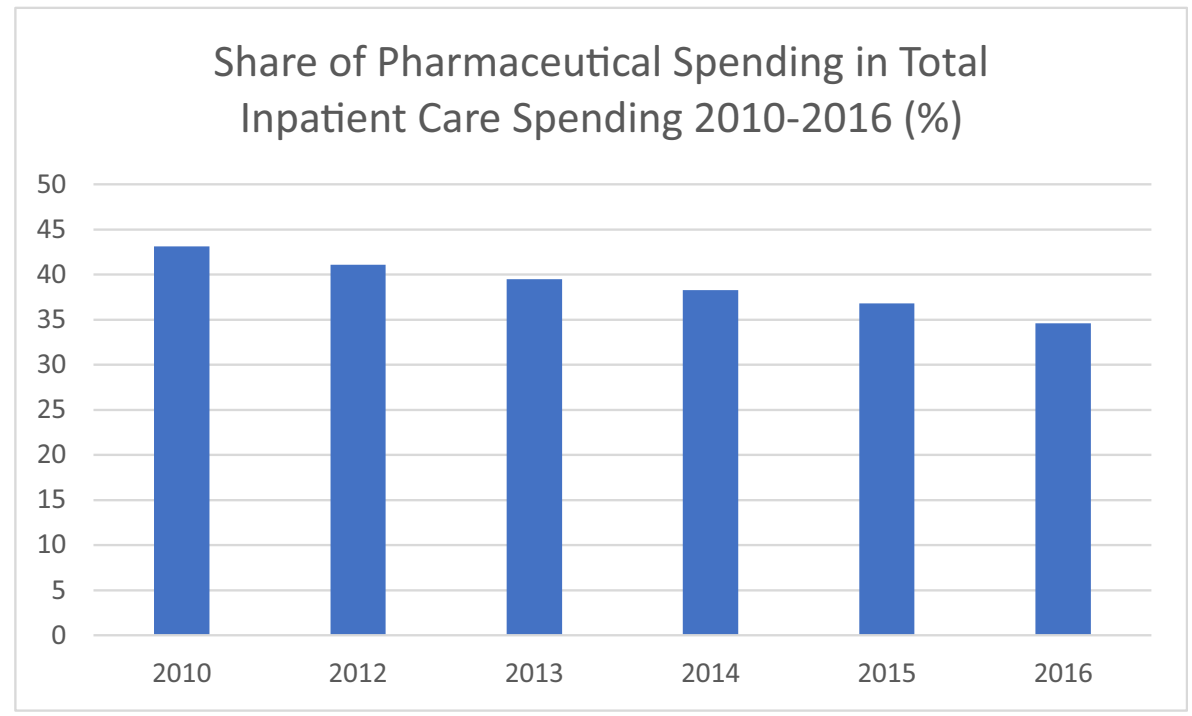

Fig. 3 Share of Pharmaceutical Spending in Total Inpatient Care Spending 2010-2016 (\%). Data source: China Health and Family Planning Statistical Yearbook 2017 
and spurring the development of large public hospitals. To strengthen primary care, Contracted Family Doctor Service was rolled out; the reimbursement rate was raised at the primary level, and the profession of general practitioners regained attention. To control the share of pharmaceuticals and supplies in health expenditure, the state introduced policies controlling abusive use of medical consumables and "two-invoices" mechanism in drug distribution. Furthermore, drug margins were canceled in public hospitals and replaced by higher medical service fees. In the following, we shall give a more detailed account of these measures. The variety of the actions taken, with their limited success, illustrate the continued challenges ahead when a country moves towards achieving the goal of providing equitable, high-quality healthcare services for everyone in the country.

\section{Medical insurance system}

\section{Merging of two medical insurance systems}

To break through the fragmentation and subsequent inefficiency, waste, and even fraud in medical insurance, some provinces in China have begun merging the medical insurance systems for urban and rural residents respectively.

A brief history of the two systems helps to understand the merger. In 2002, the central committee of CPC proposed the establishment of the basic medical insurance scheme for rural residents. In 2003, many localities piloted the scheme, and in some places, urban residents were put under that as well. Later on, some places tried to build up the urban resident basic medical insurance scheme, which was approved by the State Council for piloting in 2007. Later on, this scheme was implemented in different places. In 2016, the State Council issued the Opinions on the merging of the two schemes, and by 2017, 23 provinces have merged their two schemes and the new schemes was put under the Department of Human Resources and Social Security, instead of the Provincial Health Commissions (He 2017, 4-5).

It marks remarkable progress after the birth of the three basic medical insurance systems that now cover most of the Chinese people (Lei et al. 2017, 23-24). However, for its pros and cons, time is still needed.

\section{Raising reimbursement at the primary level}

As mentioned earlier, tertiary care institutions are crowded, but there is overcapacity at the primary care level. There have been attempts to encourage people to seek care at a more appropriate level. However, merely raising the reimbursement ratio at primary care has proved to be a failure in guiding patients to the "idle" primary care institutions. Furthermore, it is believed that reducing the reimbursement ratio in high-level treatment will harm the interests of some groups of people, in a substantial amount, especially those with lower socioeconomic status and with poor health conditions (Shen 2017, 24). Policy makers have been quite aware of this and have been seeking appropriate methods to improve the situation, but this remains one of the persistent challenges for improving healthcare delivery in China. 


\section{Real-time cross-provincial settlement of inpatient care fees}

By 15 November 2017, all the provincial platforms of medical insurance information have been connected with the national information system for medical insurance systems, 7801 health facilities have been designated as cross-provincial settlement facilities, and more than $90 \%$ of designated tertiary health facilities have joined the network for real-time cross-provincial settlement of inpatient care fees (Dong and Zhi 2017). This move aims at facilitating cross-provincial settlement of inpatient care fees, as the population of China now has a higher mobility rate than in the past, and inpatient care fees are often burdensome.

\section{Improving delivery system to strengthen the quality of primary care}

\section{Encouraging establishment of medical alliances}

Currently, four models of medical alliances exist (State Council Information Office 2017): (1) the urban model, in which tertiary public hospitals take the lead, with association with the community services; ( 2 the medical consortiums on the county level; (3) the cross-regional specialist alliance represented by the pediatric alliance led by the Beijing Children's Hospitals; and (4) the telemedicine cooperation network established by the Sino-Japanese Friendship Hospital.

There are two principles in the development of the Medical Alliances: (1) making full use of the strength of medical centers in the first-tier or second-tier cities, especially their advantages in the research, innovation, guidance, and demonstration, to help the rural primary care and (2) guiding the local governments to reach the goal of developing a highly integrated but well-tiered healthcare system.

However, the question of how to mobilize the initiative of all stakeholders and to clarify their responsibility is yet to be answered.

\section{Promoting the contracted family doctor service}

The State Council issued guidance about this system in June 2016 (NHFPC 2016). The new move aims to provide people with comprehensive, integrated, and synergetic primary care. It was piloted in 200 public hospitals in 2016. It aimed at reaching a coverage ratio of over $30 \%$ for the general public, $60 \%$ for the vulnerable groups by 2017 , and $100 \%$ for the general public by 2020 . The elderly, pregnant women, children, the disabled, and patients suffering from chronic diseases such as hypertension, diabetes, tuberculosis, and severe mental disorders were prioritized.

At present, family doctors mainly are the registered general practitioners in the stateowned primary healthcare institutions. To expand the provider reservoir, the state welcomes qualified village doctors and retired clinicians to join. Private healthcare institutions are also encouraged to sign a contract with clients, with the same payment as the public institutions.

The Family Doctor's Contracted Service was carried out in the form of teams led by family doctors, joined by community nurses and public health physicians. Pharmacists, health managers, counselors, and social workers sometimes also participate. 
The aim of the "contracted service" is to provide primary care, public health, and health management services, including the diagnosis and treatment of common and frequently encountered diseases, instructions on proper medication, and referrals to higher-level health facilities.

However, despite reported high coverage rate among residents for this new service, online posts disclose the discontent from the physicians and the public. The physicians worry that they would not get paid after they provide services, and the people complained that they barely receive any real services.

\section{General practice}

With several decades' technological advances and development, Chinese hospital departments and healthcare professionals now have been highly or even overly specialized. Such specialization has led to difficulties in the management of people with co-morbidity, which has become more prominent with China's fast advancing aging of the population. In light of this situation, a focus on general practice and general practitioners has received renewed attention.

Many preeminent hospitals, such as Beijing University First Hospital and Henan Provincial People's Hospital, have opened General Practice Clinics. Universities, such as Peking University, reopened the departments of general practice after about 20 years of closure. Training standards of general practitioners have been discussed by educators and special funding provided to attract more talents. Hopefully, this would inject fresh blood for general practice in China.

\section{Cost control}

\section{Anti-abuse of medical consumables}

For a long time, the abuse of and the high cost of medical consumables have been scolded by many as one of the main reasons for the high cost of healthcare in China. To solve the problem, the State Council issued a new guideline in 2015 State Council, requiring that all public hospitals reduce their consumptions of medical supplies by $30 \%$. However, such a rule was criticized by the public and the clinicians, because it may cause difficulty at the end of a year when the supply quota has run out, but patients would still need medical supplies.

\section{"Two-invoice" mechanism in drug distribution}

The two-invoice mechanism that aims at reducing drug price was introduced in 2017. It mandates that during the procurement of drugs, only two invoices are allowed. The drug manufacturers shall issue a value-added tax invoice to distributors, and the distributors should give another invoice distributor to the hospitals when the hospitals buy. Such a measure tries to reduce costs by eliminating profit margins at multiple layers generated in the distribution process. 


\section{Re-shuffling financing: cancellation of mark-up and introduction of medical service fees}

In 2016, the central government decided to cancel all the drug sale mark-ups in public hospitals, which used to bring substantial revenue to the hospitals. At nearly the same time, higher medical service fees were charged in these hospitals. For example, in Beijing, the visit to a consultant/expert level doctor increased from $5 \mathrm{RMB}$ to $50 \mathrm{RMB}$ $(6.8 \mathrm{RMB} \approx 1 \mathrm{USD})$.

However, complaints have been voiced by healthcare providers and the public. Clinicians reported that the extra fee charged from patients did not go to them. Patients thought the doctors obtained all the additional fees. Those without local medical insurance complained of the high service fee.

\section{8: healthcare reform in the new era}

China has come a long way in the development of its healthcare system and is moving forward towards the goal of providing high-quality services equitably to all of its citizens. In this paper, we have demonstrated the achievements but also the obstacles and challenges along the way. Xi Jinping, the president of China, in the 2017 People's Congress, emphasized the importance of healthcare for all the Chinese people, and the need for equity has been given special attention. President Xi has stressed that "socialism with Chinese characteristics has entered a new era and that the major contradictions in China have been transformed into contradictions between the people's growing needs for a better life and the unbalanced and inadequate development." (Xi 2017). He also pointed out that,

In work on public wellbeing there are still many areas where we fall short, and poverty alleviation remains a formidable task. There are still large disparities in development between rural and urban areas, between regions, and in income distribution; and our people face many difficulties in employment, education, healthcare, housing, and elderly care.

Several recent developments are worth noting. First, the former National Health and Family Planning Committee (NHFPC) was transformed into the National Health Commission (NHC) in early 2018. The National Health and Family Planning Committee was a merged government agency established in 2013. It was the result of a merger of the former Ministry of Health and the old National Population and Family Planning Committee. Hopefully, the NHC will take on an overarching role in healthcare, healthcare reform, population aging, and tobacco control, among others.

Secondly, the management of the New Rural Cooperative Health-care Scheme was taken over by the newly established National Medical Security Bureau, which reports directly to the State Council. Previously, the NRCHS was managed by the NHFPC. We hope that the convergence of management would help ease problems caused by medical insurance system fragmentation. 


\section{Conclusion}

China's UHC has undergone a tumultuous journey. After the birth of the people's republic, with Mao Zedong and his colleagues' pursuit of socialist welfare for all, UHC was realized, although in a very rudimentary way. During the free-market economy, experiments initiated by Deng Xiaoping, UHC nearly became a mirage. The socialist country is now rethinking and experimenting with new ways for UHC. Despite challenges, due to China's geographically unbalanced development and the widening gap of income and interests among its people, the movement towards universal health coverage, with equitable access for everyone to high-quality healthcare services, is inevitable in China.

\section{References}

Beijing Social Insurance Fund Management Center. 2017. Notice on issues related to the participation and payment of basic medical insurance for urban residents in Beijing 2017. http://www.bjrbj.gov. cn/LDJAPP/search/zxfgdetail_new.jsp?no=201609011314264199. Accessed 14 Feb 2019.

Blumenthal, David, and William Hsiao. 2015. Lessons from the East-China's rapidly evolving health care system. New England Journal of Medicine 372 (14): 1281-1285. https://doi.org/10.1056 /NEJMp1410425.

Center for Health Statistics and Information, NHFPC. 2015. Analysis report on the fifth national health service survey (2013). http://www.nhfpc.gov.cn/ewebeditor/uploadfile/2016/10/20161026163512679.pdf. Accessed 14 Feb 2019.

Chan, Margaret. 2017. Ten years in public health, 2007-2017: report by Dr Margaret Chan, DirectorGeneral, World Health Organization. Geneva: World Health Organization https://www.who. int/publications/10-year-review/en/. Accessed 24 Jan 2018.

Chen, Fei-Yan, Lian-Yun Zhang, Wen-Xiu Yang, Ji Xu, and Da Luo. 2013. Analysis of current situation of primary care system. Chinese Hospital Management 33 (3): 26-27. https://doi.org/10.3969/j.issn.10015329.2013.03.011.

China National Statics Bureau. 2017. China health and family planning statistical yearbook 2017. Beijing: China Union Medical College Press.

Chu, Fuling. 2013. Calculation of medical expenses reimbursement rate of China's urban and rural basic medical insurances. China Medical Insurance 3: 35-37. https://doi.org/10.3969/j.issn.16743830.2013.3.9.

Das, Jishnu, Liana Woskie, Ruma Rajbhandari, Kamram Abbasi, and Ashish Jha. 2018. Rethinking assumptions about delivery of healthcare: implications for universal health coverage. $B M J$ 361: k1716. https://doi.org/10.1136/bmj.k1716.

Data Bank of the World Bank Group. 2017. Life expectancy at birth, total (years): China. https://data. worldbank.org/indicator/SP.DYN.LE00.IN?locations=CN. Accessed 27 Jan 2018.

Dong, Xiao-Hong, and Qiang Zhi. 2017. Ten new healthcare reform policies in 2017: 'two-invoices system' to promote shuffling. Economic Information Daily, 29 December 2017. http://yuqing.people.com.cn/n1 /2017/1229/c394871-29736555.html. Accessed 29 Dec 2017.

He, Wen-Jiong. 2017. Accelerating the establishment of a unified basic medical insurance system for urban and rural residents. China's Medical Insurance 11: 4-5.

Huang, Yanzhong. 2002. The Paradoxical transition in China's health system. Harvard Health Policy Review 3(1). http://www.hcs.harvard.edu/ epihc/currentissue/spring2002/huang.php. Accessed 28 Jan 2018.

Lei, Hai-Chao, Xuan Cheng, and Zhi-Nan Zhou. 2017. Quantitative study on the development of basic medical insurance schemes in China: a mixed model based on UHC. Chinese Health Economics 36 (4): 23-28. https://doi.org/10.7664/CHE20170406.

Li, Keqiang. 2014. Report on the work of the government. China Daily, last modified 17 March 2014. http://language.chinadaily.com.cn/news/2014-03/17/content_17350891.htm. Accessed 13 Feb 2019.

Li, Jie, and Kai Ye. 2013. Analysis and improvement strategy of China's drug pricing system. China health management 30 (2): 102-105. https://doi.org/10.3969/j.issn.1004-4663.2013.02.008 
Lin, Min-Gang. 2002. Public policy analysis of the rural cooperative medical system in China. Jianghai Academic Journal 3: 91-96. https://doi.org/10.3969/j.issn.1000-856X.2002.03.015.

Liu, Kun. 2018. Report of the state council on the allocation and use of central budget for health care. Ministry of Finance. http://www.mof.gov.cn/zhengwuxinxi/caizhengxinwen/201812/t20181224_3102786.htm. Accessed 10 Feb 2019.

Marten, Robert, Diane McIntyre, Claudia Travassos, Sergey Shishkin, Long-De Wang, Srinath Reddy, and Jeanette Vega. 2014. An assessment of progress towards UHC in Brazil, Russia, India, China, and South Africa (BRICS). The Lancet 384 (9960): 2164-2171. https://doi.org/10.1016/S0140-6736(14)60075-1.

Ministry of Health Statistical Information Center. 2005. The third national health service survey. China Hospital 9 (1): 3-11. https://doi.org/10.3969/j.issn.1671-0592.2005.01.003.

National Health and Family Planning Committee. 2016. Notice on the issuance of guidance on promoting the family doctor contracted community service. NHFPC Document [2016] No.1. http://www.nhfpc.gov. cn/tigs/s3577/201606/e3e7d2670a8b4163b1fe8e409c7887af.shtml. Accessed 21 Jan 2018.

National Health Commission. 2019. The 2019 national health work conference held in Beijing. Last modified 8 January 2019. http://www.gov.cn/xinwen/2019-01/08/content_5355783.htm. Accessed 13 Feb 2019.

National People's Congress. 2015. Law on pharmaceutical products management of People's Republic of China. http://www.npc.gov.cn/npc/zfjc/zfjcelys/2017-06/27/content_2024479.htm. Accessed 20 Nov 2018.

OECD. 2017. Pharmaceutical spending (Indicator). https://doi.org/10.1787/998febf6-en. Accessed 20 Nov 2018.

Rubinstein, Adolfo. 2018. Building more effective health care coverage in Argentina. The BMJ Opinion, 22 May 2018. https://blogs.bmj.com/bmj/2018/05/22/adolfo-rubinstein-building-more-effective-health-carecoverage-in-argentina/. Accessed 28 Feb 2019.

Shen, Cheng-Feng. 2017. Necessity to adhere to the principles of basic medical insurance in the reimbursement rate adjustment. China Medical Insurance 6: 24.

State Council Information Office, People's Republic of China. 2017. Four mature models of medical alliances building. http://www.scio.gov.cn/32344/32345/35889/36475/zy36479/Document/1548448/1548448.htm. Accessed 20 Jan 2018.

Tang, Shenglan, Jingjing Tao, and Henk Bekedam. 2012. Controlling cost escalation of healthcare: making UHC sustainable in China. BMC Public Health 12 (Suppl 1): S8. https://doi.org/10.1186/1471-2458-12S1-S8.

The People's Daily. 2017. National health input growing by leaps and bounds. Last modified 9 February 2017. http://www.gov.cn/xinwen/2017-02/09/content_5166640.htm. Accessed 8 Feb 2019.

Wang, Hong-Man. 2017. What reduces people's 'sense of gain' in health care. People's Tribune 9: 64-66. https://doi.org/10.3969/j.issn.1004-3381.2017.09.023.

Wen, Jiabao. 2011. Report on the work of the government. China Daily, last modified 27 February 2014. http://language.chinadaily.com.cn/2014npccppcc/2014-02/27/content_17309663.htm. Accessed 10 Feb 2019.

World Health Organization. 2010. The World Health Organization Report 2010: Health systems financing: the path to universal coverage. Geneva: World Health Organization. https:/www.who.int/whr/2010/en/. Accessed 10 April 2018.

World Health Organization. 2018. Universal health coverage and health financing. http://www.who. int/health_financing/universal_coverage_definition/en/. Accessed 7 April 2018.

$\mathrm{Xi}$, Jinping. 2017. Speech on the first plenary session of the $19^{\text {th }}$ CPC central committee. xinhuanet.com, last modified 31 December 2017. http://www.xinhuanet.com/politics/2017-12/31/c_1122191624.htm. Accessed 10 Nov 2018.

Zhang, $\mathrm{Xu}$. 2015. An introduction to social medical insurance schemes. TCM Healthy Life-Nurturing 11: 1115.

Publisher's Note Springer Nature remains neutral with regard to jurisdictional claims in published maps and institutional affiliations. 